\title{
Correlation between two-dimensional micro-CT and histomorphometry for assessment of the implant osseointegration in rabbit tibia model
}

Hao-Zhen Lyu ${ }^{1,2}$ (D) and Jae Hyup Lee ${ }^{1,2,3^{*}}$

\begin{abstract}
Background: Histology is considered as a gold standard for analyzing bone architecture. However, histomorphometry is a destructive method and only offers the bone information of a limited location. Micro-computed tomography $(\mu \mathrm{CT})$ is a non-destructive technology and provides a slice at any site. The aim of this study was to compare the correlation of the Bone-to-Implant Contact ratio (BIC) between 2D micro- $\mathrm{CT}(\mu \mathrm{CT})$ and histomorphometry and to investigate a method for assessing the osseointegration of the implant by $2 \mathrm{D} \mu \mathrm{CT}$.

Methods: A total of 18 implants were divided into three groups (6 implants per group), and inserted into the rabbit tibia defects as follow: implant only (Implant group), implant with $\beta$-TCP/hydrogel (TCP group), implant with rhBMP-2 loaded $\beta$-TCP/hydrogel composite (BMP-2 group). After 4 weeks of implantation, the specimens were collected to take the micro-CT scan with an aluminum filter and performed H\&E staining on the undecalcified sections. The 2D $\mu C T$ slices were chosen at an angle of $0^{\circ}, 45^{\circ}, 90^{\circ}$ and $135^{\circ}$ with the representative histological section to measure BIC. And the correlations between BICs of $2 \mathrm{D} \mu \mathrm{CT}$ and BICs of histology were evaluated.

Results: In each group, BICs at the same sites measured by histomorphometry and corresponding 2D $\mu C T$ presented the same trend and shown no significant difference between the two methods $(P>0.05)$. BICs of histological sections and BICs of corresponding 2D $\mu \mathrm{CT}$ slices presented a strong correlation in the implant group $(\gamma=0.74, P=0.09)$, a moderate correlation in the TCP group $(\gamma=0.46, P=0.35)$, a weak correlation in the BMP-2 group $(\gamma=0.30, P=0.56)$. In the implant group, the relationship between BIC-Mean- $\mu \mathrm{CT}$ s and BICs-Histology has presented a significant linear correlation $(\gamma=0.84, P=0.04)$.
\end{abstract}

Conclusions: Integrating bone information of several 2D $\mu \mathrm{CT}$ slices in different sites to measure BIC is a feasible method for assessing the implant osseointegration.

Keywords: Bone-implant interface, Histology, Osseointegration, X-ray microtomography

\footnotetext{
* Correspondence: spinelee@snu.ac.kr

'Department of Orthopedic Surgery, SMG-SNU Boramae Medical Center, Boramae-ro 5-gil 20, Dongjak-gu, Seoul 07061, South Korea

${ }^{2}$ Department of Orthopedic Surgery, College of Medicine, Seoul National University, Seoul, South Korea

Full list of author information is available at the end of the article
}

(c) The Author(s). 2021 Open Access This article is licensed under a Creative Commons Attribution 4.0 International License, which permits use, sharing, adaptation, distribution and reproduction in any medium or format, as long as you give appropriate credit to the original author(s) and the source, provide a link to the Creative Commons licence, and indicate if changes were made. The images or other third party material in this article are included in the article's Creative Commons licence, unless indicated otherwise in a credit line to the material. If material is not included in the article's Creative Commons licence and your intended use is not permitted by statutory regulation or exceeds the permitted use, you will need to obtain permission directly from the copyright holder. To view a copy of this licence, visit http://creativecommons.org/licenses/by/4.0/. The Creative Commons Public Domain Dedication waiver (http://creativecommons.org/publicdomain/zero/1.0/) applies to the data made available in this article, unless otherwise stated in a credit line to the data. 


\section{Background}

In dentistry and orthopedic, the osseointegration of the implant is important to assess the stability of internal fixation. Bone-to-Implant Contact ratio (BIC), the ratio of the length of bone direct contact to the implant thread to the length of the implant thread, is measured for evaluating the osteointegration and stability of the implant [1-3].

Currently, histomorphometry is considered as the gold standard for analyzing the BIC [4]. However, the making process of the histological slide is tedious, timeconsuming, and destructive. Only a few representative cross-sections in the specific position of the implant is obtained by histological section and insufficient to provide the overall information of the implant [4-6]. Additionally, the specimen after the histomorphometry cannot be used for the other assessments.

Due to time-saving, convenience and nondestructive, micro-computed tomography $(\mu \mathrm{CT})$ has been extensively used to evaluate the structure of bony tissue. The $\mu \mathrm{CT}$ dataset could be reconstructed to observe the bone architecture in any location around the implant and analyze the parameters of bone in the region of interest (ROI). However, because of the different attenuation coefficients of bone and implant in the specimen, metallic artifacts are generated on the bone-implant interface by the metal implant [7-9]. Therefore, the artifact affects the BIC obtained using $\mu \mathrm{CT}$. Some previous studies recommend using soft filters to reduce artifacts during CT scanning, such as an aluminum or brass filter [10, 11], and using the correction functions of the analysis software during $\mathrm{CT}$ reconstruction to decrease the interference of artifacts, such as misalignment compensation, ring artifacts reduction, and beam-hardening correction [12]. Furthermore, a few studies suggested measuring BIC after excluding several voxels close to the screw surface to eliminate the artifact zone [13-15]. At present, there is no ideal method or program available for measuring $\mathrm{BIC}$ by $\mu \mathrm{CT}[16]$.

So far, the BICs have been obtained using the twodimensional (2D) $\mu \mathrm{CT}$ images or the three-dimensional (3D) $\mu \mathrm{CT}$ models by different methods. In these researches, authors detected the correlation between the BICs of $\mu \mathrm{CT}$ and the BICs of histology for investigating the feasibility whether the $\mathrm{BIC}-\mu \mathrm{CT}$ could replace the BIC-Histology to assess osseointegration [11, 17, 18]. However, the results of the correlations between the two methods were various in these studies. There were few studies to evaluate the osseointegration of the implant by integrating $2 \mathrm{D} \mu \mathrm{CT}$ slices of multiple locations [6].

Due to the insufficient amount of autografts for treatment, synthetic bone substitutes that include bone graftbased substitutes (allograft, xenograft), ceramic-based substitutes (hydroxyapatite, calcium phosphate), growth factor-based substitutes (BMPs, PRP, FGF), and their combinations are used to promote bone regeneration $[19,20]$. The development of new bone substitutes need to evaluate the osteogenesis efficacy in vivo experiment. If the implant osseointegration could be assessed by micro-CT, it saves time and cost.

In this study, we loaded recombinant human bone morphogenetic protein-2 (rhBMP-2) on the $\beta$-tricalcium phosphate $(\beta-\mathrm{TCP}) /$ hydrogel composite and inserted it with the dental implant into the rabbit tibial bone defect model to promote bone formation [21, 22]. We measured the BICs on the $2 \mathrm{D} \mu \mathrm{CT}$ images at different sites of the implants using the manually measuring method that was performed in the histomorphometry. The aim of this study was to compare the correlation of BIC between $2 \mathrm{D} \mu \mathrm{CT}$ and histomorphometry and to investigate a method for assessing the osseointegration of the implant by $2 \mathrm{D} \mu \mathrm{CT}$.

\section{Methods}

Preparation of rhBMP-2 loaded hydrogel composite

The $\beta$-TCP microspheres (Cerectron Co., Korea) were made by a spray-dry method for spherical particles in a 45-75 $\mu \mathrm{m}$ diameter range. The poloxamer 407 (BASF, German) at $18-22 \%$ concentration presents a sol-gel transition under $25^{\circ} \mathrm{C}$ and exhibits the gel status at $37^{\circ} \mathrm{C}$. The $0.4 \mathrm{~g} \beta$-TCP microspheres, $0.4 \mathrm{ml}$ poloxamer 407 hydrogel at $35 \%$ concentration and $0.3 \mathrm{ml}$ of 1.33 $\mathrm{mg} / \mathrm{ml}$ E.coli-derived rhBMP-2 (Daewoong Pharm. Co., Korea) solution were mixed in situ that we previously described [23, 24]. The final concentration of rhBMP-2 in the hydrogel composite was $50 \mu \mathrm{g} / \mathrm{ml}$.

\section{In vivo}

Three New Zealand white male rabbits $(3-3.5 \mathrm{~kg})$ with no disease signs were used for the animal experiment in this study. The rabbits were raised in the standard cages and had an acclimation period for at least 1 week before surgical procedure. Zolazepam-tiletamine (Zoletil ${ }^{\circledR}, 15$ $\mathrm{mg} / \mathrm{kg}$, Virbac Co., Korea) and xylazine hydrochloride (Rompun ${ }^{\oplus} 7.5 \mathrm{mg} / \mathrm{kg}$, Bayer Ltd., Korea) were intramuscularly injected for the general anesthesia. A skin incision was made on the anteromedial of the tibia along the longitudinal line. The fascia and periosteum on the tibia shaft were removed to expose the cortical bone. Three round defects $(4 \mathrm{~mm}$ diameter) were drilled in a tibia shaft, and the distance between each defect was at least $12 \mathrm{~mm}$ to avoid interacting in osteogenesis. The same surgical procedure was performed on the bilateral tibia of the three rabbits. A total of 18 defects were randomly divided into three groups (6 implants per group). The dental implants $(\varnothing 4 \mathrm{~mm}, 8.5 \mathrm{~mm}$ length, MegaGen Co., Korea) inserted into the rabbit tibia defect models as follow: Implant group (implant only), TCP group 
(implant with $0.1 \mathrm{ml} \beta$-TCP/hydrogel), and BMP-2 group (implant with $0.1 \mathrm{ml} \beta-\mathrm{TCP} /$ hydrogel loading $5 \mu \mathrm{g}$ rhBMP-2). In the TCP group and BMP-2 group, the 0.1 $\mathrm{ml} \beta$-TCP/hydrogel or $0.1 \mathrm{ml} \beta-\mathrm{TCP} /$ hydrogel contained $5 \mu \mathrm{g}$ rhBMP-2 was placed in the defect by syringe, and then the dental implant was inserted into the bone defect. The three defects of each tibia belong to the same group. The cefazolin (300 mg, Yuhan Co., Korea) was intramuscularly injected 2 days for antibiotic therapy. After 4 weeks of implantation, the implant specimens were harvested to perform the micro-CT scanning and histology analysis. This study was permitted by the Institutional Animal Care and Use Committee (IACUC No. 11-0231) in the Clinical Research Institute of Seoul National University Hospital.

\section{Micro-CT processing and analysis}

Each harvested tibia was divided into three specimens containing implants. The specimens were scanned using the Skyscan 1173 micro-CT (Kontich, Belgium) with a $0.5 \mathrm{~mm}$ aluminum filter at $60 \mu \mathrm{A}, 130 \mathrm{kV}$ and a resolution of $20 \mu \mathrm{m}$. The micro-CT raw dataset was reconstructed by the NRecon Software (Version 1.5.1.1, Skyscan, Belgium) with ring artifact correction at 5 and beam hardening correction at $40 \%$. According to the geometric markers of the implants and host bone, the $2 \mathrm{D} \mu \mathrm{CT}$ slices matching with the representative histological slices were acquired by the Dataview Software (Version 1.4.0.0, Skyscan, Belgium) (Fig. 1). Next, the optimal threshold (min 60, max 90) of the newly formed bone around the implant was identified in micro-CT using the corresponding histologic sections as a reference. The $2 \mathrm{D} \mu \mathrm{CT}$ binary images, then, were converted to halftone images to distinguish air and soft tissue

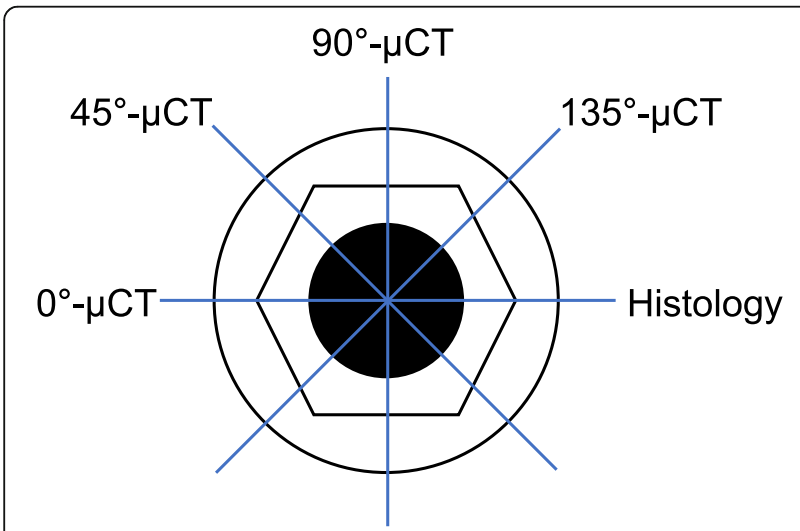

Fig. 1 Sites of the micro-CT slices and the histological section for $\mathrm{BIC}$ measurement. The 2D micro-CT slice, named $0^{\circ}-\mu \mathrm{CT}$, was corresponding with the representative histological section. The 2D micro-CT slices at the interval of $45^{\circ}, 90^{\circ}$, and $135^{\circ}$ from the histological section, named $45^{\circ}-\mu \mathrm{CT}, 90^{\circ}-\mu \mathrm{CT}$, and $135^{\circ}-\mu \mathrm{CT}$, were selected to calculate BIC (blank), bone (red) and implant (green) with the CTAnalyzer Software (Version 1.12.0.0, Bruker, Skyscan) (Fig. 2). The upper four grooves in each side of the implant on the $2 \mathrm{D} \mu \mathrm{CT}$ slices were chosen to measure BICs by the Image J Software (US National Institutes of Health, Bethesda) [2, 25]. One layer of voxels at the junction of the implant and bone were excluded to measure BICs. In addition, the other $2 \mathrm{D} \mu \mathrm{CT}$ slices were chosen at interval of $45^{\circ}, 90^{\circ}$ and $135^{\circ}$ with the representative histological section by the Dataview Software, and processed in the same procedures as above to calculate BIC (Figs. 1 and 2). Furthermore, the average of the BIC measured at four sites of the implant was calculated in the group which has strong correlation between $2 \mathrm{D} \mu \mathrm{CT}$ and histology.

\section{Histomorphometry analysis}

The specimens were fixed in the $10 \%$ formalin for 5 days and dehydrated in 100\% alcohol. The specimens then were infiltrated in the chemical curing resin (methacrylate-based) and embedded with benzoyl peroxide. The blocks were cut along the longitudinal axis of the implant using EXAKT BS-3000 N (Norderstedt, Germany) and sectioned at $4 \mu \mathrm{m}$ thickness along the sagittal plane through the center of the implant. The sections have performed the Hematoxylin and Eosin staining (H\&E). The bone formation around the implant threads was observed with light microscopy (Olympus, Japan), and the four grooves identical to the $2 \mathrm{D} \mu \mathrm{CT}$ slices were selected to calculate BIC using the Image J Software (Fig. 2) [25, 26].

\section{Statistical analysis}

Statistical analysis was performed by SPSS (Version 23, IBM, USA). A paired t-test was used to compare the two methods of calculating BIC $[6,18]$. The Pearson's correlation coefficients $(\gamma)$ was used to evaluate the agreement between the $2 \mathrm{D} \mu \mathrm{CT}$ slices and histological sections $[6$, 18]. $P$-values $<0.05$ were considered to be statistically significant.

\section{Results}

A total of 18 implants of the three groups (6 implants per group) were collected to measure the BIC for assessing osseointegration. The BIC obtained by the representative histological sections was named BIC-His. The 2D $\mu \mathrm{CT}$ slice matching with the representative histological section was named $0^{\circ}-\mu \mathrm{CT}$. The $2 \mathrm{D} \mu \mathrm{CT}$ slices at a $45^{\circ}$, $90^{\circ}$, and $135^{\circ}$ interval to the histological section were named $45^{\circ}-\mu \mathrm{CT}, 90^{\circ}-\mu \mathrm{CT}$, and $135^{\circ}-\mu \mathrm{CT}$, respectively.

There was no significant difference between the BICs obtained by histology and 2D $\mu \mathrm{CT}$ in each group $(P>$ 0.05) (Table 1). The BICs of histological sections and BICs of $0^{\circ}-\mu \mathrm{CT}$ slices presented a strong correlation in the implant group $(\gamma=0.74, \quad P=0.09)$, a moderate 


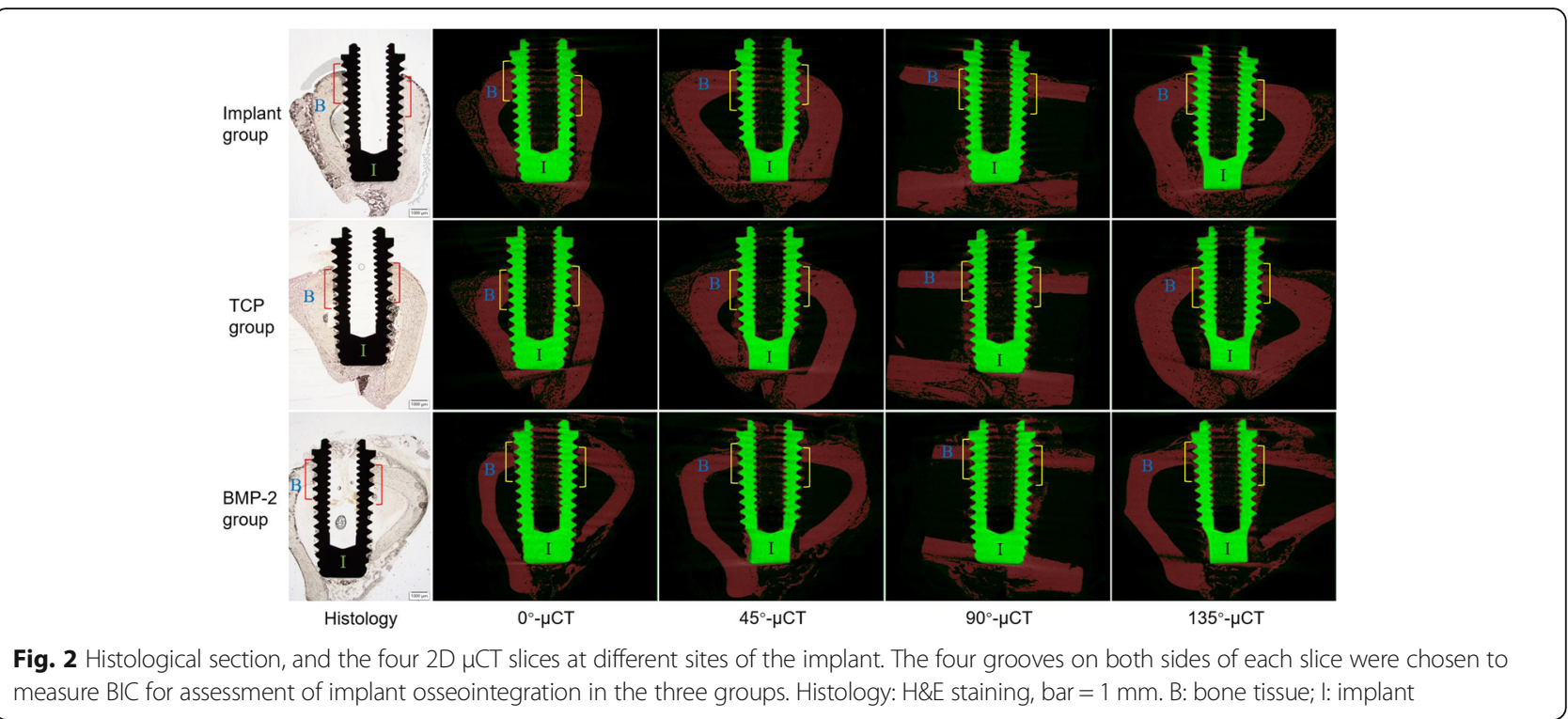

correlation in the TCP group $(\gamma=0.46, P=0.35)$, a weak correlation in the BMP-2 group $(\gamma=0.30, P=0.56)$ (Table 1, Fig. 3).

Furthermore, the diverse correlations were shown between BICs- $\mu \mathrm{CT}$ at different sites $\left(\right.$ at $0^{\circ}, 45^{\circ}, 90^{\circ}$, and $\left.135^{\circ}\right)$ and $\mathrm{BICs}-\mathrm{His}$ in the implant group. There were strong positive correlations of BICs between $2 \mathrm{D} \mu \mathrm{CT}$ slices (at $0^{\circ}$, $45^{\circ}$, and $90^{\circ}$ ) and histological sections, and the moderate correlation was shown between $135^{\circ}-\mu \mathrm{CT}$ slices and histological sections $(\gamma=0.74,0.81,0.71$, and $0.41 ; P=0.09$, $0.05,0.11$, and 0.42 , respectively) (Table 2).

In addition, the mean of BICs at four different sites in each implant was calculate to assess the osseointegration of the overall implant, named BIC-Mean- $\mu$ CTs. In the implant group, the relationship between BIC-Mean$\mu \mathrm{CTs}$ and BICs-His has presented a significant linear correlation $(\gamma=0.84, P=0.04$, Fig. 4$)$.

\section{Discussion}

In the bone regeneration research, the specimen for histomorphometry must be obtained by sacrificing the experimental animals and could only offer the bone information of the limited locations. On the contrary, for the small animals (mouse and rat), micro-CT data could be achieved under anesthesia and provide a $2 \mathrm{D}$ $\mu \mathrm{CT}$ slice of any site. If the implant osseointegration could be speculated by the micro-CT slices, we could observe the osteogenesis at different time points through one animal and reduce the death of experimental animals. In addition, we consider that the BIC calculated by integrating bone information of several $2 \mathrm{D} \mu \mathrm{CT}$ slices of different locations is more comprehensive to assess the osseointegration of the implant than BIC obtained by histomorphometry in part location.

In this study, we used an aluminum filter in scanning and adjust the correction functions of the analysis software to reduce the artifacts in the micro-CT reconstruction. The critical procedure in the present study is to select the threshold of newly formed bone in micro-CT analysis. The bone tissue is isolated from air, soft tissue (bone marrow), and metallic implant by the different specific threshold values. The ISO 50\% method based on the grayscale histogram is commonly used to determine the bone threshold $[18,27]$. However, the low-mineralized bone has a similar threshold value with bone marrow or soft tissue, and their threshold ranges unavoidably overlap with each other.

Table 1 Comparison of BICs between histological sections and the corresponding micro-CT slices $\left(0^{\circ}-\mu C T\right)$ in each group

\begin{tabular}{|c|c|c|c|c|c|c|}
\hline Group & $\mathrm{N}$ & BIC-Histology & BIC- $0^{\circ}-\mu C T$ & Mean difference & $\begin{array}{l}\text { Pearson's correlation } \\
(P \text {-value })\end{array}$ & $\begin{array}{l}P \text {-value } \\
\text { (Paired } t \text {-test) }\end{array}$ \\
\hline Implant group & 6 & $67.02 \pm 6.21$ & $61.95 \pm 13.05$ & $5.07 \pm 9.44$ & $0.74(0.09)$ & 0.25 \\
\hline TCP group & 6 & $31.94 \pm 9.84^{*}$ & $34.08 \pm 7.37^{*}$ & $-2.14 \pm 9.17$ & $0.46(0.36)$ & 0.59 \\
\hline BMP-2 group & 6 & $47.97 \pm 21.36$ & $41.94 \pm 11.65^{*}$ & $6.03 \pm 21.01$ & $0.30(0.56)$ & 0.51 \\
\hline
\end{tabular}

Values are presented as mean \pm standard deviation

$B I C$ Bone-to-Implant Contact ratio, $\mu C T$ 2D $\mu C T$ slice, $N$ number of specimens

*: $P$-value $<0.05$, the significant difference compared with Implant group 

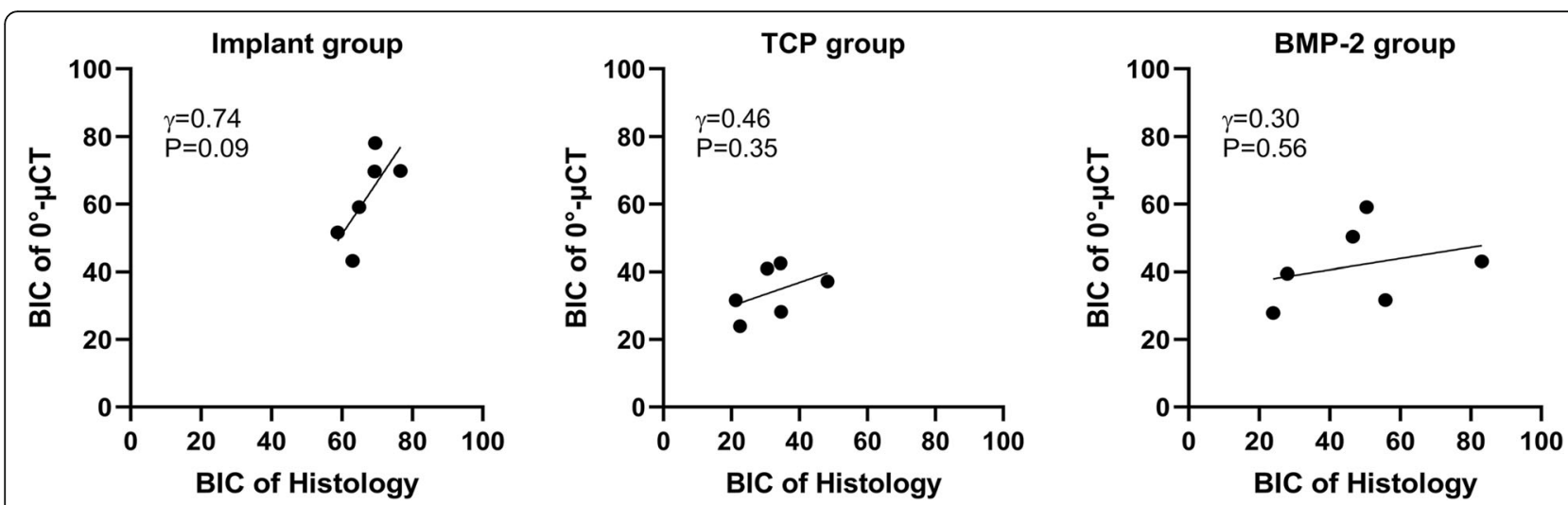

Fig. 3 Correlation of BICs between the histological section and $0^{\circ}-\mu \mathrm{CT}$. A strong correlation was presented in the implant group, a moderate correlation was shown in the TCP group, and a weak correlation was exhibited in the BMP-2 group. BIC: Bone-to-Implant Contact ratio; $0^{\circ}-\mu C T$ : corresponding with the histological section; Y: Pearson's correlation coefficient; P: P-value

Hence, the threshold of bone is chosen by the ISO $50 \%$ method has a deviation $[27,28]$. Due to the high resolution, the low-mineralized bone can also be clearly distinguished from other tissues in the undecalcified histological slide. In order to improve the accuracy of the threshold, the histological sections were served as a reference to define the optimal threshold ( $\min 60$, max 90) for new bone in micro$\mathrm{CT}$ analysis. Whereas, these operations cannot completely eliminate the interference of artifacts. Consequently, we excluded one layer of voxels at the junction between the bone and the thread to reduce the influence of artifacts in measuring $\mathrm{BIC}$ on the $2 \mathrm{D} \mu \mathrm{CT}$ slice $[11,12]$.

In each group, BICs at the same sites measured by histomorphometry and corresponding $2 \mathrm{D} \mu \mathrm{CT}$ presented the same trend and shown no significant difference between the two methods (Table 1). Moreover, a strong correlation $(\gamma=0.74)$ was found between BIC of $0^{\circ}-\mu \mathrm{CT}$ and BIC of histology in the implant group (Table 1, Fig. 3). Because of micro-CT scanned an object at a certain interval, it was difficult to find the $2 \mathrm{D} \mu \mathrm{CT}$ slice that was exactly matching with the histological slice. Therefore, the correlation coefficient between the BICs measured by the two modalities was slightly reduced. In the TCP group and the BMP-2 group, the moderate and weak correlations were detected between BIC of 2D $\mu \mathrm{CT}$ and BIC of histology at the identical site (Fig. 3). We considered that the residual $\beta$-TCP granules affect the correlation coefficient in the TCP group and the BMP-2 group. The $\beta$-TCP granules in the hydrogel were not completely degraded within 4 weeks and could be distinguished from the bony tissue in the undecalcified histological section. Therefore, $\beta$-TCP was excluded in the BIC measurement for histomorphometry. On contrary, the $\beta$-TCP could not be distinguished from the bone in micro-CT and was identified as the new bone in the BIC measurement. Therefore, the BIC obtained by 2D $\mu \mathrm{CT}$ slice could be used to assess the implant osseointegration, when no bone graft-based substitutes and ceramic-based substitutes remain.

In the implant group, various correlation coefficients were shown between BICs of the $2 \mathrm{D} \mu \mathrm{CT}$ at different sites and BICs of the representative histological sections (Table 2). It is demonstrated that the BIC acquired from histology of a specific location cannot illuminate the osseointegration of the whole implant or that at other sites. Therefore, we calculated the mean of BICs of the four $\mu \mathrm{CT}$ slices $\left(\right.$ at $0^{\circ}, 45^{\circ}, 90^{\circ}$, and $135^{\circ}$ ) of each implant to assess the osseointegration of the entire implant. A high correlation coefficient $(\gamma=0.84)$ was shown between BIC-Mean- $\mu \mathrm{CTs}$ and BIC-Histology (Fig. 4). However, the correlation will be altered when changing the site of histological section or increasing the number of $\mu \mathrm{CT}$ slices for calculating BIC-Mean- $\mu \mathrm{CT}$ s. And the more $2 \mathrm{D} \mu \mathrm{CT}$ slices are used to calculate the mean of

Table 2 Correlations of BICs between micro-CT slices at different sites and histological sections in the implant group

\begin{tabular}{|c|c|c|c|c|c|}
\hline Comparison & $\mathbf{N}$ & BIC- $\mu C T$ & BIC-Histology & Pearson's correlation $(\gamma)$ & $P$-value \\
\hline $0^{\circ}-\mu C T$ vs Histology & 6 & $61.95 \pm 13.05$ & $67.02 \pm 6.21$ & 0.74 & 0.09 \\
\hline $45^{\circ}-\mu \mathrm{CT}$ vs Histology & 6 & $60.24 \pm 11.89$ & & 0.81 & 0.05 \\
\hline $90^{\circ}-\mu \mathrm{CT}$ vs Histology & 6 & $58.64 \pm 11.27$ & & 0.71 & 0.11 \\
\hline $135^{\circ}-\mu C T$ vs Histology & 6 & $58.33 \pm 11.05$ & & 0.41 & 0.42 \\
\hline
\end{tabular}

Values are presented as mean \pm standard deviation

$B I C$ Bone-to-Implant Contact ratio, $\mu C T$ 2D $\mu C T$ slice, $N$ number of specimens

$P$-value $<0.05$ : statistically significance 


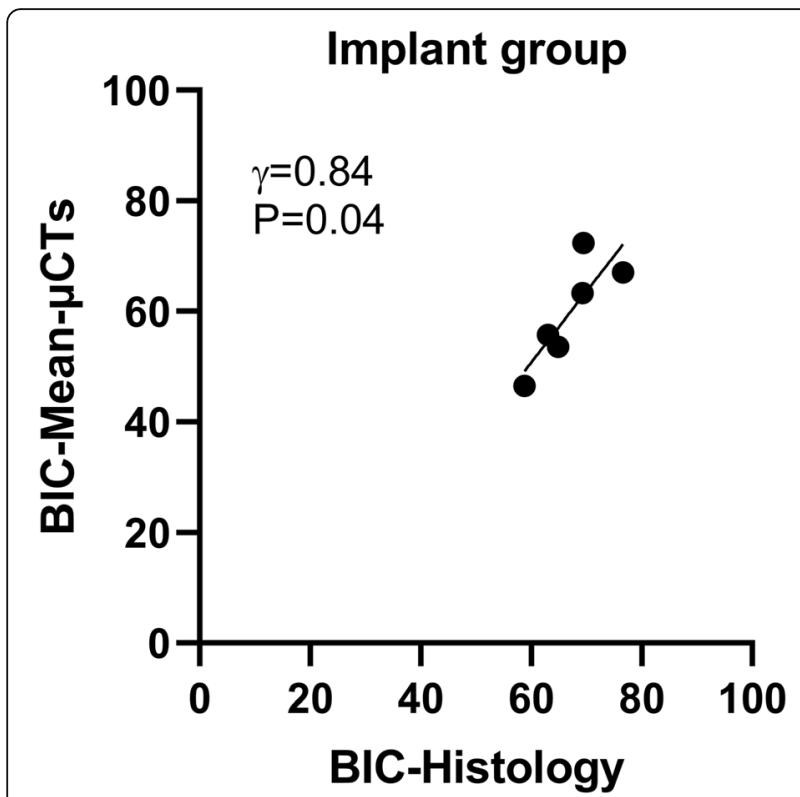

Fig. 4 Significantly linear correlation between BIC-histology and BICMCT-mean in the implant group. BIC: Bone-to-Implant Contact ratio; BIC- $\mu$ CT-mean: mean of BICs on the four $\mu C T$ slices; $\gamma$ : Pearson's correlation coefficient; P: P-value

BICs, the closer the BIC-Mean- $\mu$ CTs is to the osseointegration of the implant.

Some limitations exist in the present study. First, due to the small sample size, $P$ values had biases in the present study. The second limitation is the small number of $2 \mathrm{D}$ $\mu \mathrm{CT}$ slices used for calculating the mean of BICs. Additionally, the method of minimizing artifacts still needs to be optimized. The BIC-Mean- $\mu$ CTs supplies comprehensive information of the entire implant osseointegration, while the BIC-Histology offers an accurate assessment of the osseointegration at a specific site.

\section{Conclusion}

The method that integrating bone information of several $2 \mathrm{D} \mu \mathrm{CT}$ slices in different sites to measure BIC is feasible to assess the implant osseointegration, although the method needs further optimization.

\section{Acknowledgements}

Not applicable.

\section{Authors' contributions}

HZL: designed the study, performed experiment, analyzed data and wrote the manuscript. JHL: designed the study, conceived and supervised the research, and reviewed the paper. The authors read and approved the final manuscript.

\section{Funding}

This work was supported by the Korea Medical Device Development Fund grant funded by the Korea government (the Ministry of Science and ICT, the Ministry of Trade, Industry and Energy, the Ministry of Health \& Welfare, the Ministry of Food and Drug Safety) (Project Number: KMDF_PR_20200901_0151).

\section{Availability of data and materials}

All data generated or analyzed in this study are included in this published article.

\section{Declarations}

\section{Ethics approval and consent to participate}

This study was permitted by the Institutional Animal Care and Use Committee (IACUC No. 11-0231) in the Clinical Research Institute of Seoul National University Hospital.

\section{Consent for publication}

All authors have consented to the submission of this manuscript for publication.

\section{Competing interests}

The authors declare that they have no competing interests.

\section{Author details}

${ }^{1}$ Department of Orthopedic Surgery, SMG-SNU Boramae Medical Center, Boramae-ro 5-gil 20, Dongjak-gu, Seoul 07061, South Korea. ${ }^{2}$ Department of Orthopedic Surgery, College of Medicine, Seoul National University, Seoul, South Korea. ${ }^{3}$ Institute of Medical and Biological Engineering, Medical Research Center, Seoul National University, Seoul, South Korea.

Received: 2 February 2021 Accepted: 24 March 2021

Published online: 13 April 2021

\section{References}

1. Meagher MJ, Parwani RN, Virdi AS, Sumner DR. Optimizing a microcomputed tomography-based surrogate measurement of bone-implant contact. J Orthop Res. 2018;36(3):979-86. https://doi.org/10.1002/jor.23716.

2. Choi J-Y, Park J-I, Chae JS, Yeo I-SL. Comparison of micro-computed tomography and histomorphometry in the measurement of bone-implant contact ratios. Oral Surg Oral Med Oral Pathol Oral Radiol. 2019;128(1):8795. https://doi.org/10.1016/j.oooo.2018.12.023.

3. Albrektsson T. Hard tissue implant interface. Aust Dent J. 2008;53(1):S34-S8. https://doi.org/10.1111/j.1834-7819.2008.00039.x.

4. Bernhardt R, Kuhlisch E, Schulz MC, Eckelt U, Stadlinger B. Comparison of bone-implant contact and bone-implant volume between 2D-histological sections and 3D-SRHCT slices. Eur Cell Mater. 2012;23:237-48. https://doi. org/10.22203/eCM.v023a18.

5. Sennerby L, Wennerberg A, Pasop F. A new microtomographic technique for non-invasive evaluation of the bone structure around implants. Clin Oral Impl Res. 2001;12(1):91-4. https://doi.org/10.1034/j.1600-0501.2001.012001 091.X

6. Park YS, Yi KY, Lee IS, Jung YC. Correlation between microtomography and histomorphometry for assessment of implant osseointegration. Clin Oral Implants Res. 2005;16(2):156-60. https://doi.org/10.1111/j.1600-0501.2004.01 083.x.

7. Boas FE, Fleischmann D. CT artifacts: causes and reduction techniques, Imaging Med. 2012;4(2):229-40. https://doi.org/10.2217/iim.12.13.

8. Vandeweghe S, Coelho PG, Vanhove C, Wennerberg A, Jimbo R. Utilizing micro-computed tomography to evaluate bone structure surrounding dental implants: a comparison with histomorphometry. J Biomed Mater Res B Appl Biomater. 2013;101(7):1259-66. https://doi.org/10.1002/jbm.b.32938.

9. Li JY, Pow EHN, Zheng LW, Ma L, Kwong DLW, Cheung LK. Quantitative analysis of titanium-induced artifacts and correlated factors during micro-CT scanning. Clin Oral Implants Res. 2014;25(4):506-10. https://doi.org/10.1111/ clr.12200.

10. Van Oossterwyck H, Duyck J, Vander Sloten J, Van Der Perre G, Jansen J, Wevers $\mathrm{M}$, et al. Use of microfocus computerized tomography as a new technique for characterizing bone tissue around oral implants. J Oral Implantol. 2000;26(1):5-12. https://doi.org/10.1563/1548-1336(2000)026< 0005:TUOMCT>2.3.CO;2.

11. Stoppie N, Waerden JP, Jansen JA, Duyck J, Wevers M, Naert IE. Validation of microfocus computed tomography in the evaluation of bone implant specimens. Clin Implant Dent Relat Res. 2005;7(2):87-94. https://doi.org/1 0.1111/j.1708-8208.2005.tb00051.x.

12. Faria Vasconcelos K, Santos Corpas L, Silveira BM, Laperre K, Padovan LE, Jacobs R, et al. MicroCT assessment of bone microarchitecture in implant 
sites reconstructed with autogenous and xenogenous grafts: a pilot study. Clin Oral Implants Res. 2017;28(3):308-13. https://doi.org/10.1111/clr.12799.

13. Liu S, Broucek J, Virdi AS, Sumner DR. Limitations of using micro-computed tomography to predict bone-implant contact and mechanical fixation. J Microsc. 2012;245(1):34-42. https://doi.org/10.1111/j.1365-2818.2011.03541.x.

14. Butz F, Ogawa T, Chang T-L, Nishimura I. Three-dimensional bone-implant integration profiling using micro-computed tomography. Int J Oral Maxillofac Implants. 2006;21(5):687-95.

15. Sarve $H$, Friberg B, Borgefors $G$, Johansson C. Introducing a novel analysis technique for Osseointegrated dental implants retrieved 29 years Postsurgery. Clin Implant Dent Relat Res. 2013;15(4):538-49. https://doi.org/1 0.1111/j.1708-8208.2011.00413.X.

16. Choi J-YC, Choi CA, Yeo I-SL. Spiral scanning imaging and quantitative calculation of the 3-dimensional screw-shaped bone-implant interface on micro-computed tomography. J Periodontal Implant Sci. 2018;48(4):202-12. https://doi.org/10.5051/jpis.2018.48.4.202.

17. Schouten C, Meijer GJ, van Den Beucken JJJP, Spauwen PHM, Jansen JA. The quantitative assessment of peri-implant bone responses using histomorphometry and micro-computed tomography. Biomaterials. 2009; 30(27):4539-49. https://doi.org/10.1016/j.biomaterials.2009.05.017.

18. Bissinger O, Probst FA, Wolff KD, Jeschke A, Weitz J, Deppe H, et al. Comparative 3D micro-CT and 2D histomorphometry analysis of dental implant osseointegration in the maxilla of minipigs. J Clin Periodontol. 2017; 44(4):418-27. https://doi.org/10.1111/jcpe.12693.

19. Nandi SK, Roy S, Mukherjee P, Kundu B, De DK, Basu D. Orthopaedic applications of bone graft \& graft substitutes: a review. Indian J Med Res. 2010;132:15-30.

20. Wang W, Yeung KWK. Bone grafts and biomaterials substitutes for bone defect repair: a review. Bioact Mater. 2017;2(4):224-47. https://doi.org/10.101 6/j.bioactmat.2017.05.007.

21. Lee J, Kim J, Baek H-R, Lee K, Seo J-H, Lee H-K, et al. Fabrication of an rhBMP-2 loaded porous $\beta$-TCP microsphere-hyaluronic acid-based powder gel composite and evaluation of implant osseointegration. J Mater Sci Mater Med. 2014;25(9):2141-51. https://doi.org/10.1007/s10856-014-5250-0.

22. Chung H, Kim S, Chung SH. Clinical outcome of Beta-Tricalcium phosphate use for bone defects after operative treatment of benign tumors. Clin Orthop Surg. 2019;11(2):233-6. https://doi.org/10.4055/cios.2019.11.2.233.

23. Lyu H-Z, Lee JH. The efficacy of rhBMP-2 loaded hydrogel composite on bone formation around dental implants in mandible bone defects of minipigs. Biomater Res. 2020;24(1):5. https://doi.org/10.1186/s40824-020-01 83-9.

24. Lee JH, Ryu MY, Baek H-R, Seo J-H, Lee K-M, Lee J-H. Generation of an rhBMP-2-loaded beta-tricalcium phosphate/hydrogel composite and evaluation of its efficacy on peri-implant bone formation. Biomed Mater. 2014;9(5):055002. https://doi.org/10.1088/1748-6041/9/5/055002.

25. Bissinger O, Götz C, Jeschke A, Haller B, Wolff K-D, Kaiser P, et al. Comparison of contact radiographed and stained histological sections for osseointegration analysis of dental implants: an in vivo study. Oral Surg Oral Med Oral Pathol Oral Radiol. 2018;125(1):20-6. https://doi.org/10.1016/j. oooo.2017.06.118.

26. Botzenhart U, Kunert-Keil C, Heinemann F, Gredes T, Seiler J, Berniczei-Roykó Á, et al. Osseointegration of short titan implants: a pilot study in pigs. Ann Anat. 2015;199:16-22. https://doi.org/10.1016/j.aanat.2014.02.011.

27. Kowaluk T, Wozniak A. A new threshold selection method for X-ray computed tomography for dimensional metrology. Precis Eng. 2017;50:44954. https://doi.org/10.1016/j.precisioneng.2017.06.020

28. Bernhardt R, Scharnweber D, Müller B, Thurner P, Schliephake H, Wyss $P$, et al. Comparison of microfocus- and synchrotron $X$-ray tomography for the analysis of Osteointegration around Ti6Al4V-implants. Eur Cell Mater. 2004;7: 42-51. https://doi.org/10.22203/eCM.v007a05.

\section{Publisher's Note}

Springer Nature remains neutral with regard to jurisdictional claims in published maps and institutional affiliations.

\section{Ready to submit your research? Choose BMC and benefit from:}

- fast, convenient online submission

- thorough peer review by experienced researchers in your field

- rapid publication on acceptance

- support for research data, including large and complex data types

- gold Open Access which fosters wider collaboration and increased citations

- maximum visibility for your research: over $100 \mathrm{M}$ website views per year

At BMC, research is always in progress.

Learn more biomedcentral.com/submissions 